Article

\title{
Sustainable Intelligent Charging Infrastructure for Electrification of Transportation
}

\author{
Prahaladh Paniyil ${ }^{1, *(D)}$, Vishwas Powar $^{1}$ (D) and Rajendra Singh ${ }^{1,2}$ (D) \\ 1 Holcombe Department of Electrical and Computer Engineering, Clemson University, \\ Clemson, SC 29634, USA; vpowar@clemson.edu (V.P.); srajend@clemson.edu (R.S.) \\ 2 Department of Automotive Engineering, Clemson University, Clemson, SC 29634, USA \\ * Correspondence: ppaniyi@clemson.edu
}

check for updates

Citation: Paniyil, P.; Powar, V.; Singh, R. Sustainable Intelligent Charging Infrastructure for Electrification of Transportation. Energies 2021, 14, 5258. https://doi.org/10.3390/ en14175258

Academic Editors: Ilan Aharon and Alon Kuperman

Received: 30 June 2021

Accepted: 24 August 2021

Published: 25 August 2021

Publisher's Note: MDPI stays neutral with regard to jurisdictional claims in published maps and institutional affiliations.

Copyright: (c) 2021 by the authors. Licensee MDPI, Basel, Switzerland. This article is an open access article distributed under the terms and conditions of the Creative Commons Attribution (CC BY) license (https:/ / creativecommons.org/licenses/by/ $4.0 /)$.

\begin{abstract}
For sustainable electrification of surface transportation, a viable charging infrastructure is necessary. Firstly, this paper focuses on emphasizing the viability of a free fuel-based photovoltaics and/or wind turbines and lithium-ion battery-based power network to enable sustainable electric power. The importance of power electronics for a DC-based power network and extremely fast charger based on DC power is presented. Finally, the core design concepts of intelligent charging infrastructure using an intelligent energy management system are discussed. The paper aims to cover all aspects associated with a clean, reliable, efficient, and cost-effective solution to the novel charging infrastructure.
\end{abstract}

Keywords: photovoltaics; lithium-ion battery; DC fast charging; HVDC

\section{Introduction}

Other than the COVID-19 pandemic, the increased risks to the world due to climate change have become one of the most dominant issues today. The world must incorporate major changes in sources that are responsible for contributing to climate change. The transportation industry has been one of the major contributors to the greenhouse gas (GHG) emissions, which lead to climate change [1]. Making green energy the default option has the potential to cut greenhouses gases emissions by millions of tons [2]. The most advanced ultra-low-cost sustainable solution must be pursued to fight climate challenges. The purpose of this paper is to provide sustainable solution for the electrification of transportation to meet the goals to curb climate change related challenges undertaken by various nations across the globe.

Electrification of transportation provides a sustainable solution to the emissions issue. Currently, the electric vehicle market comprises of a hybrid electric vehicle (HEV), plug-in hybrid electric vehicle (P-HEV), fuel cell electric vehicle (FCEV), and battery electric vehicle (BEV). Both HEVs and P-HEVs play a very small role in GHG emissions reduction, since a major source of energy is fossil fuel. FCEVs are based on hydrogen as their fuel source and are claimed to operate at zero GHG emissions as hydrogen combustion does not generate any emissions. However, the efficiency of operation of FCEVs is an overlooked fact. Reference [3] shows a comparative analysis of the efficiencies of BEVs, FCEVs, and conventional gasoline vehicles. BEVs dominate FCEVs in both well-to-tank and tank-to-wheel efficiencies by $43 \%$ and $51 \%$, respectively, considering a $100 \%$ renewable energy source for power generation. As illustrated in the data in reference [3], the efficiency of conventional vehicles is much lower than the BEVs. Depending on the method utilized for generation of refueling hydrogen, the environmental impact can be calculated. Furthermore, 100\% carbon neutral hydrogen production is not cost-effective and will be discussed in the following section of this paper. Thus, due to the complexities involved in hydrogen production and the cost of hydrogen generated from renewable sources, FCEV cars are not an economically viable and green replacement of conventional gasoline-based vehicles. 
This paper focuses on establishing a relationship between the electricity generation and transportation infrastructure to deploy a sustainable and clean network for the future. Electrification of the transportation sector also comprises the electrification of railways, air, and water transportation other than surface transportation. However, this paper will emphasize electrification of surface transportation to discuss the effectiveness of BEVs and their impact to the electric grid. Henceforth in this paper, the term EV will be used for BEV due to the relevance and scope of the paper. The trend in the EV growth is going to continue in future and this will poise a new demand to the electricity grid. EV charging needs to be addressed to ensure a smooth transition from fossil-fuel-based transportation to electric transportation. Currently, the lack of charging infrastructure and the associated concern of running out of charge on the road are some of the main reasons for not purchasing EVs [4]. One other major concern is the lack of availability of the chargers [4]. EV manufacturers are making steady progress to address the range of EVs. As an example, Tesla recently announced the range of Model 3 to $635 \mathrm{~km}$ [5]. To address the second concern, it is important to implement a novel electrical power network that can address this increased demand from the EV industry. A number of studies have been conducted on the impact of EVs and their charging demand across the world [6-13]. The major inference from these studies is that the EV charging framework needs to be optimized to sustain the demand in the future. As shown in references [14] and [15], different optimization and control strategies have been researched to reduce the greenhouse emissions generation of EV charging and optimize the impact of EV charging on the grid requirements, respectively. Mainly there are three types of charging strategies [16]. The first charging strategy is based on charging after last trip which does not involve any smart charging (dumb strategy). The second strategy is based on a profit-maximization scenario to charge the EV when electricity rates are low due to reduced demand. The final strategy is based on a power factor control scenario wherein the power factor is regulated to maintain the node voltage by supplying reactive power. The power factor control scenario was concluded as the best charging scenario. However, little research attention has been directed towards isolating the charging network to minimize the impact on the electricity grid. The strain in the current grid infrastructure can be minimized by adopting a novel sustainable power network dedicated for the EV charging framework. In this scenario, the power factor control is not necessary as there will be no involvement of reactive power as discussed in the later sections of this paper.

To address the concern for charging times of EVs to enable greater adoption, fast charging is the way to move forward for complete electrification of the surface transportation sector. A grid connected fast charging infrastructure can pose various problems for the grid. The effect can be seen on the grid stability, supply, and demand balance of the grid, utility system assets, system voltage and phase regulation of the grid, current harmonics of the grid, and on the system losses [17]. Thus, it is important to realize that control and optimization strategies alone cannot curtail these impacts on the grid. Our proposed concept emphasizes on the elimination of grid impacts by realizing an off-grid concept to sustain the new electricity demand from EVs. Cost is another important factor to be considered while analyzing EV charging strategies to enable maximum adoption of EVs by the public at large. According to reference [18], even though the majority of residents in New South Wales in Australia are willing to pay an annual levy for the incorporation of smart charging infrastructure in the area, a substantial percentage of the residents were unwilling to pay any levy. Thus, it is critical that the proposed fast charging infrastructure should be available to individuals and various type of businesses and other entities at minimum costs. The components utilized in conversion from alternating current (AC) to direct current (DC) power is another factor which contributes to the overall cost of the charging infrastructure. By employing a DC network and eliminating power conversion needs, the network can achieve sustainability as well as reliability [19]. The energy source for such a network should focus on minimum energy costs and currently the only free 
fuel-based low-cost energy sources are solar and wind energy. The advantages of utilizing solar photovoltaics (PV) with complimentary wind energy are also discussed in this paper. Apart from fast charging infrastructure, only charging EV at night schedules for residential customers has a significant impact on the grid. In developing countries such as South Africa, due to lack of renewable energy penetration in the grid, the EV charging nighttime demand can generate a greater carbon footprint compared to an internal combustion engine (ICE) vehicle [20]. This defeats the purpose of switching to electrification of the transportation sector. Reference [20] also showcases a solar energy-based model to charge EVs at workplaces during the day to minimize the grid impact and carbon footprint. Thus, a similar model must be incorporated to charge EVs even at fast charging stations to minimize the impact on the utility grid. Fast chargers require high power connections to the grid and can cause substantial loads with increasing number of EVs. The control, optimization, and Time-Of-Use (TOU) strategies alone cannot absorb the load demand from the increasing EV penetration in the current market. In the following section, we will discuss the viability of the novel and sustainable power network for EV charging. A photovoltaics (PV), wind, and lithium-ion battery-based DC power network for fast charging is described in Sections 2 and 3. In Section 4, we have described the additional factors that must be considered to reinforce our proposed charging infrastructure. The last section deals with the conclusions of the paper.

\section{What Is Sustainable Electric Power Network?}

A sustainable power network must be based on renewable energy sources owing to the grave issue of climate change. In this section we have discussed the key characteristics of sustainable electric power network.

\subsection{Free Fuel-Based Energy Conversion}

The use of fossil fuels has been responsible for all economic and political events since the energy crisis of 1973 [21]. For sustainable global economic growth, a fossil fuel-based economy must be replaced by a free fuel-based economy. Although nuclear power has its positive aspect with respect to greenhouse emissions, nuclear power is not cost-effective. Providing cost-effective safety is one major challenge. A report released recently by the Union of Concerned Scientists (UCS) analyzed the designs of a number of so-called "advanced" non-light-water nuclear reactors currently at the development stage and found that they are no better-and in some respects significantly worse-than the currently used light-water reactors [22]. Nuclear disaster related final cost of Japan's Fukushima reactor will approach one trillion dollars [23]. Waste management is another major issue. The costs associated with the waste management and construction of plants are enormous. Lastly, nuclear resources are not renewable. Ultimately, the world will run out of it. For economic and safety reasons, there is no need to build new nuclear reactors. Hydroelectric power stations are another major source of energy generation. However, due to increasing temperatures and weather temperaments such as heat waves across the globe due to climate change-related activities, the risk of losing water levels in reservoirs has increased in the past few years [24]. Major utility companies are conserving water utilization to satisfy peak summer loads that rely on hydroelectric power generation [24] Thus, the utilization of a power source should be independent of factors that can majorly affect its efficiency of operation.

Thomas Edison in 1931 stressed the importance of free fuel energy sources specifically solar energy for generating electrical power by quoting "We are like tenant farmers chopping down the fence around our house for fuel when we should be using nature's inexhaustible sources of energy-Sun, wind, and tide. I'd put my money on the sun and solar energy. What a source of power! I hope we don't have to wait until oil and coal run out before we tackle that" [25]. Energy from free fuel renewable sources does not undergo the variability in cost as fossil fuel-based energy sources do, due to their abundancy. The sun is the most abundant source of energy known to mankind and hence the utilization 
of solar energy is extremely viable and necessary. The cost variation trend of various technologies for electrical power generation technologies are discussed in reference [26]. Photovoltaics have provided the lowest cost followed by onshore wind. Furthermore, in a recent publication [27], we have shown the availability of favorable power outputs from wind energy in locations where PV outputs are not in the greatest intensity. Therefore, it is most viable to adopt this free fuel-based energy conversion technique for generating sustainable electric power for EV charging infrastructure with PV at the center and complimentary wind energy systems to support it.

\subsection{Ultra-Low Cost}

As mentioned in the previous section, the variability in the cost of fossil fuel-based energy sources has made it extremely difficult to sustain the power network on these resources. Constantly falling prices of electrical power generated by PV have provided PV electrical power costs as low as 1.04 cents $/ \mathrm{kWh}$, which represents the lowest cost of electrical power generated by any other technique. [28]. However, if PV is to be considered as the most feasible of renewable energy generation techniques, the cost of storage also must be taken into consideration. Fortunately, the lithium-ion batteries cost also keep falling in line with the cost reduction of PV modules [29]. This reduction in battery cost is fueled by the increasing demand for EVs across the globe. Based on recent cost data published by Bloomberg New Energy finance [30], the average battery pack cost in year 2020 is USD 144/kWh and is expected to be USD 61/kWh in 2030. A number of innovative manufacturing steps are in progress that will further reduce the cost of lithiumion batteries [31]. As an example, the cost of CATL's cobalt-free lithium iron phosphate battery packs have fallen below USD $80 / \mathrm{kWh}$ [32]. In a recent patent, Tesla announced a new "tables" battery cell design that will further reduce the manufacturing cost [33]. Although no one has reported manufacturing cost and performance data, solid state lithium batteries have the potential for further cost reduction. Due to constantly falling prices of batteries, there are a number of power purchasing agreements (PPAs) in place with the cost of stored electric power is about $0.02 \mathrm{USD} / \mathrm{kWh}$ [34]. The Los Angeles Department of Water and Power has signed a groundbreaking 25-year PPA with 8Minute Solar [35]. The combined price for solar energy plus storage is just 0.03.3 USD per $\mathrm{kWh}$, the lowest ever in the US and cheaper than electricity from a natural gas-powered generating plant [35].

In addition to the decreasing cost of battery packs, the employed duration for batterybased storage systems influences its economic feasibility. The employed duration for most battery storage projects is 4 to $6 \mathrm{~h}$ for different grid-tied applications such as wholesale arbitrage, load levelling, microgrid islanding, frequency regulations, and other ancillary services. The reported cost of energy storage is, therefore, based on $4 \mathrm{~h}$ of operation. As the operable duration of storage increases, the USD/kWh cost of Li-ion battery storage significantly reduces. This cost reduction for longer duration of operation can be mapped to lower power costs (USD/kW) and volume manufacturing of batteries. Based on the NREL's study [36], $4 \mathrm{~h}$ battery costs account for more than 55\% of the total installed system costs as compared to non-battery costs (labor and installation costs, land, sales tax, developer costs). For longer durations ranging from 16 to $18 \mathrm{~h}$ of battery operation, the non-battery costs become insignificant and the battery modules account for the majority of the total systems costs. The reduction in $60 \mathrm{MW}$ battery system costs for 0.5 -h of operation (USD $895 / \mathrm{kWh}$, 2018) to $4 \mathrm{~h}$ of operation (USD 380/kWh, 2018) as calculated in [37] can be extrapolated for $16-18 \mathrm{~h}$ of operation as USD 226/kWh to USD 246/kWh in 2021 [37]. For charging stations that need on-demand power outflow, energy storage costs should be calculated as per extended duration costs of 16-18 h rather than using $4 \mathrm{~h}$ leveled storage costs.

Thus, it is possible to create an ultra-low-cost sustainable power network using a combination of PV, complimentary wind, and lithium-ion battery packs. The ultra-low-cost requirement is a very important metric as it is important to sustain economic growth. As an example, due to higher electricity cost, several aluminum smelters in the US have closed or 
threatened to close due to power rates they deem too high [38]. It is important to provide cheap electricity to industries to sustain economic growth in any nation.

\subsection{Water Utilization, Ecosystem Impact, and Health Impact}

Water scarcity is one of the eminent threats faced by humanity. Access to clean and usable water is still a problem in many third world and developing countries till today. Any energy-based power infrastructure must incorporate water utilization as one of its performance metrics. It is an established fact that renewable energy sources (especially PV and wind energy systems), have the least utilization of water [39-41]. This is warranted as PV and wind energy systems do not require large scale cooling mechanisms such as coal, natural gas, or nuclear plants.

Along with water utilization, the impact of a power network on the ecosystem is also an important parameter. According to the Natural Resources Defense Council (NRDC), fossil fuel-based energy production techniques have been the major factor responsible for the pollution of land, water, and air [42]. Mining, fracking, and drilling have led to the degradation of land due to unearthing and exposing vast stretches of terrain including forests and mountains. Even after their completion, such activities destroy the qualities of the terrain and impact the wildlife habitat negatively. Similarly, water bodies, such as rivers, streams, and lakes, are also negatively impacted by these activities. Wastewater management and hazardous run-offs into these water bodies have been a major problem faced by environmentalists even today. Drilling and fracking activities for fossil fuels in oceans often lead to oil spills affecting various flora and fauna and their ecosystems altogether. Lastly, air pollution and its negative impacts can be seen by the entire world today in the form of GHG emissions leading to the issue of climate change.

Not only do these activities have a negative impact on plant and animal ecosystems, but they also have adverse health impacts for humans. According to World Health Organization (WHO) reports, approximately 1.7 million children die every year due to unclean environments [43]. Furthermore, according to [44], a strong association was found between childhood leukemia and oil and natural gas plants. In addition to this, we are all exposed to weather-related health risks due to the effects of climate change. Climate change also leads to an increase in the frequency of natural disaster, thus, posing great health risks as an aftereffect other than the loss of life and damage to society.

Free fuel energy sources such as solar and wind have a minimum adverse impact on ecosystems and human health [45]. Solar and wind are the safest clean sources of energy [26]. Hence, it is very important to adopt clean energy-based systems as the power network for EV charging to sustain the ecosystems, minimize health risks, and ensure conservation of water resources.

\subsection{Resiliency against Natural and Manmade Disasters}

There has been an increased frequency of natural disasters in recent times due to climate change. The power network of the future must be able to sustain itself against these natural disasters. PV and battery-based networks are resilient against natural disasters such as geomagnetic storms caused due to coronal mass ejections from the sun [46]. Although the event of the coronal mass ejections entering the earth's atmosphere and causing a geomagnetic storm is not a frequent event, it causes significant damage to the alternating current (AC) centralized electricity network. The ability of PV, complimentary wind energy and battery-based networks to work in a decentralized system also provides the necessary security and resiliency from such events. This decentralized power network enables the electricity network in a certain region to operate without disruption due to failures in other regions. In a centralized AC-based network, the failure in one region disrupts power throughout the entire network. The resilience of PV systems against different natural disasters is discussed in reference [47]. PV systems are reliable during the majority of the natural disasters and have performed excellently when other fossil fuel-based power systems have failed [47]. Apart from natural disasters, the man-made electromagnetic 
pulse (EMP) in the atmosphere also possesses a serious risk to the electricity grid. An EMP generated through such an attack would impose severe hazards on the electrical systems in most of the nation's area [48]. The EMP burst, similar to a geomagnetic storm, can cause considerable damage to the existing AC power grid and cause long-term national power outages. The resilience of PV-based systems combined with battery storage has already been discussed and hence, these systems have greater immunity of the electrical power grid from such man-made threats as well [46].

\subsection{Access to All}

Figure 1 [49] shows the proportion of the global population that still do not have access to electricity as of 2018. Accessibility issues are mostly due to the inability of the centralized infrastructure to reach remote rural areas. The decentralized, local DC power network encompassing PV and batteries can address the accessibility even in remote rural regions. To demonstrate the effectiveness of PV systems, we combined the population density data with the availability of PV output across the world. The population density data was obtained from reference [50]. Incident solar intensity data was obtained from reference [51]. The color-coded population density map was combined with the incident solar intensity data and assigned different colors accordingly to generate the new combined data map. This is demonstrated in Figure 2. The data clearly indicate that majority of the world population can produce a substantial amount of PV power per day. Another important observation from Figure 1 [49] and Figure 2 is that in regions where there is a larger proportion of the population without access to electricity, the PV power trends are the opposite. For example, in India where the proportion of the population without access to electricity is higher, there is considerable amount of PV power according to the population density. In regions with lower population and lower PV output power intensity, such as the Scandinavian and Northern Russian territories, wind energy power output intensities are substantially greater [27]. This natural complement enables the design of a power network that can be sustained $100 \%$ on free-fuel-based sources of energy with maximum accessibility.

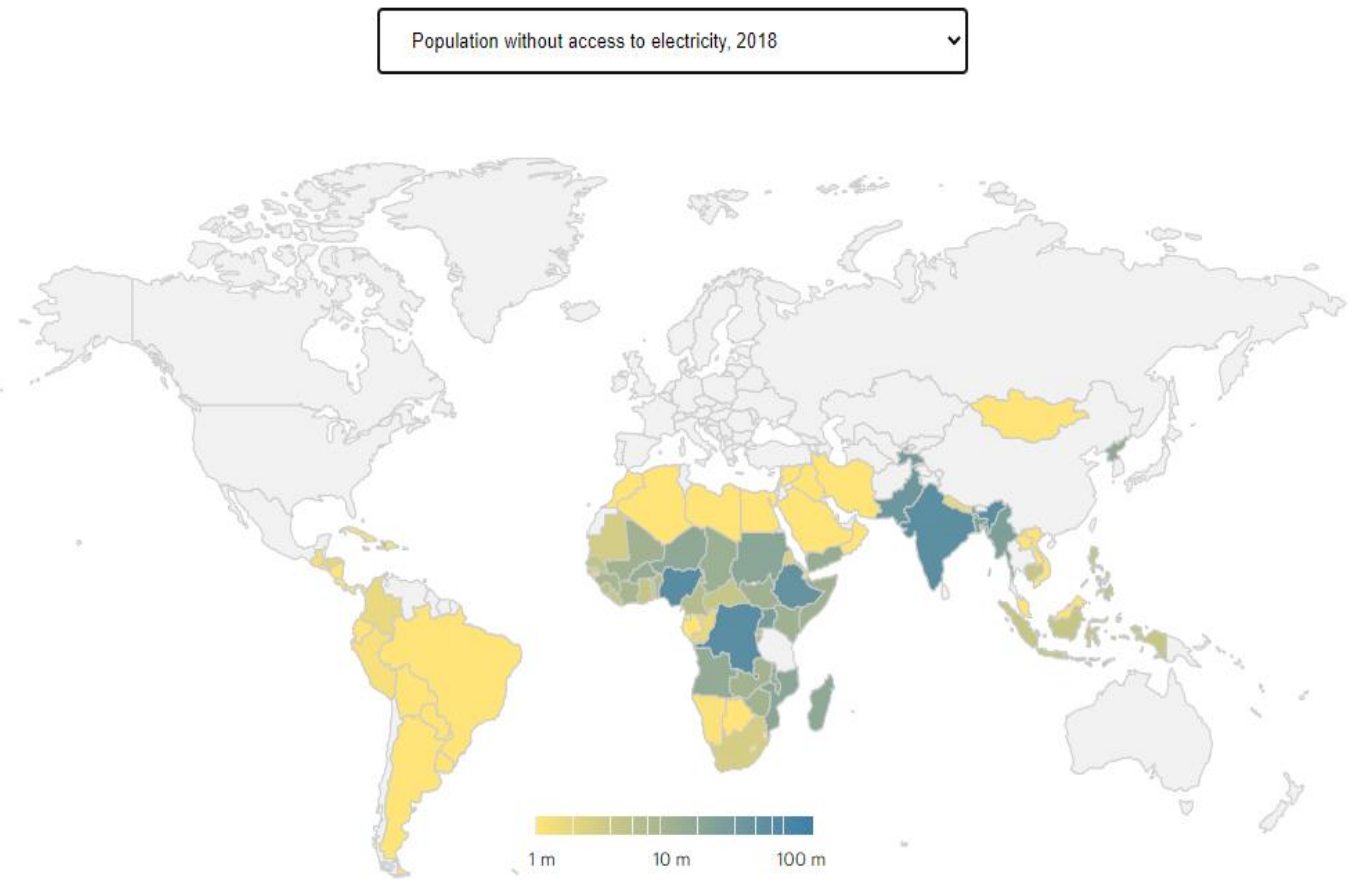

Figure 1. Population in the world without access to electricity (in millions) [49]. Source: IEA (2019) SDG7: Data and Projections. All rights reserved. 


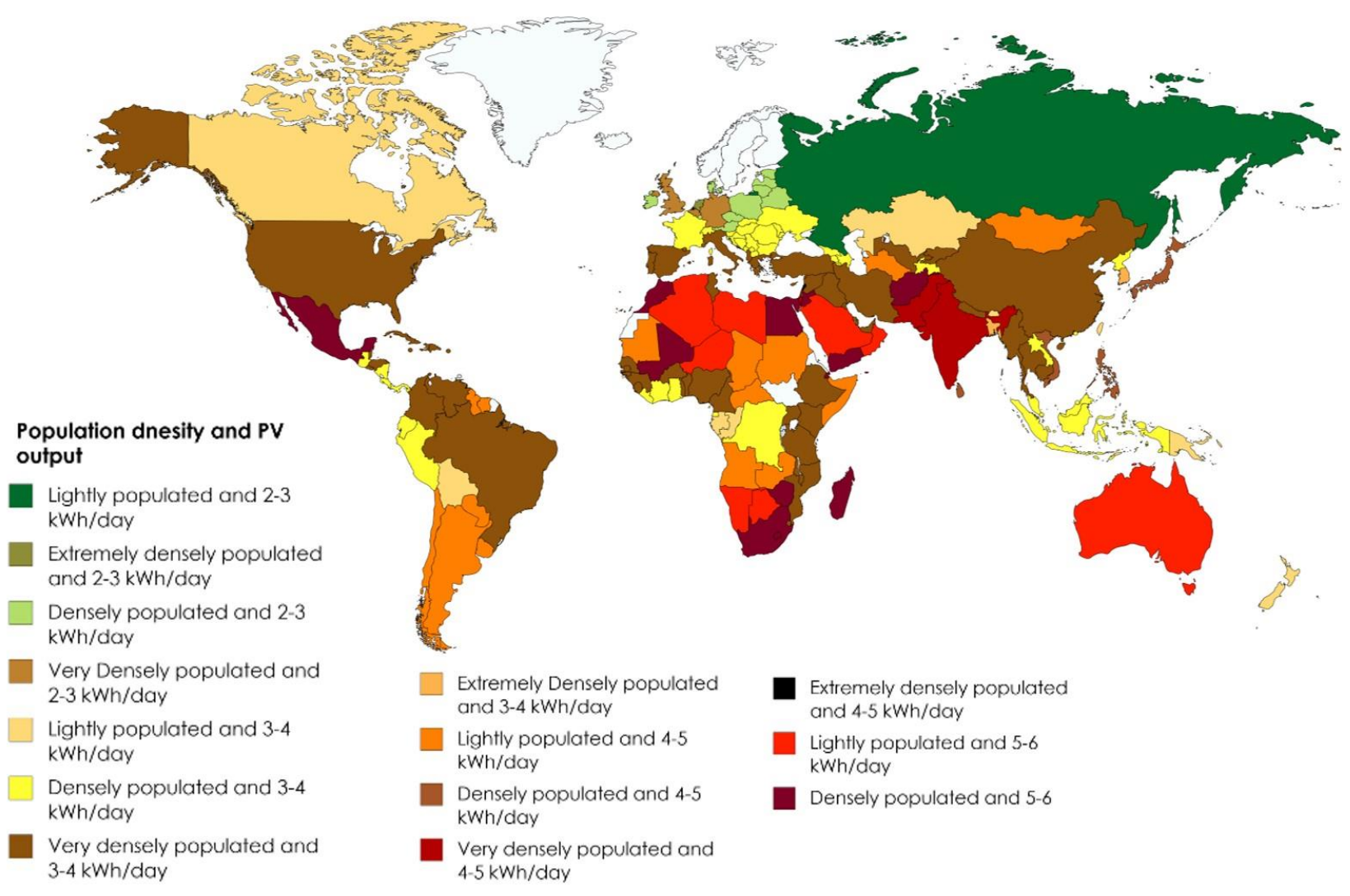

Figure 2. PV output combined with population density. The colors represent the data as indicated in the legend.

\subsection{Energy Storage}

With increasing electricity demand round-the-clock, it is important to consider storage systems for the power infrastructure. In our scope, EV charging is a dynamic load and therefore must incorporate storage systems to fulfill load demand. Natural gas-based storage systems are not considered a viable option due to its carbon emissions. Even with the novel carbon capture technologies, $100 \%$ carbon capture and storage cannot be achieved. The major storage options that are being researched by the industry are pumped hydroelectric storage, lithium-ion battery banks, and hydrogen fuel cells.

Even though pumped hydro systems dominate approximately $93 \%$ of the energy storage market, their viability as a storage alternative for $\mathrm{EV}$ charging is questionable [52]. Although pumped hydro systems can achieve greater life cycle values, in terms of response time, power density, energy density, and roundtrip efficiency, a lithium-ion battery system is the superior technology [52]. Pumped hydro systems have a geographical dependence for their operation, whereas lithium-ion systems are not affected by location to a major extent due to higher energy and power densities. These parameters hold greater value in an electric vehicle charging infrastructure as compared to life cycle. As discussed in Section 2.1, due to increasing temperatures and weather temperaments, such as heat waves across the globe due to climate change related activities, the risk of losing water levels in reservoirs has increased in the past few years. Therefore, we have chosen lithium-ion battery systems over pumped hydro systems for sustainable electric power networks. 
Apart from pumped hydro systems, hydrogen fuel cell technologies are also being considered as an energy storage alternative by the industry. Hydrogen fuel generation techniques determine the environmental feasibility of the utilized hydrogen. There are three power sources to generate the hydrogen for fuel cells. Grey hydrogen or "dirty" hydrogen is generated through the combustion of coal and hence will not be considered as a storage option in our scope due to its GHG emissions. Blue hydrogen relies on capturing and storing $90 \%$ of the carbon emission generated during the hydrogen generation process. However, it cannot completely get rid of the carbon emissions. Blue hydrogen is usually generated through natural gas-based techniques. The larger goal to tackle the climate change related challenges through increased EV adoption, remains in question by the utilization of grey and blue hydrogen. Green hydrogen is the only viable hydrogen generation technique that can be utilized to achieve minimum/zero GHG emissions. Green hydrogen is generated via an electrolysis process which consumes electric power. The electric power required for electrolysis is provided by renewable energy sources to ensure minimum emissions. However, the electrolysis process makes the generation of green hydrogen significantly more expensive than blue hydrogen [53]. The recent claims of the hydrogen fuel economy as an alternative can only be based on blue hydrogen with economic competitiveness. Blue hydrogen is being considered as a bridge or pathway to achieve a green hydrogen economy. However, issues related to green hydrogen are not being considered. The challenges associated with generation, storage, and distribution of green hydrogen are discussed in reference [54]. Therefore, it is important to realize that the hydrogen fuel economy for transportation and storage is just to ensure continued utilization of natural gas reserves by the fracking-related conglomerates. Lithium-ion battery systems are the only way forward to effectively electrify the surface transportation sector through efficient DC-to-DC charging systems.

\section{PV, Complimentary Wind, and Lithium-ion Battery-Based Power Network for DC Fast Charging}

Different type of chargers and their capabilities can be seen in Table 1 [55]. Both for Level 1 and Level 2, global standards have been developed. Extremely fast charging (XFC) is the ultimate fast charging system that covers from light duty to heavy duty vehicles and is being pursued by commercial vendors as well as by researchers. Both from energy efficiency of power network as well as cost, DC Fast charging would be the preferred charging mechanism. Passenger vehicles can survive with Level 1 and Level 2 charging mechanisms as they are charged at home and commercial places where one does not need faster charging time all the time. However, many companies such as UPS, Amazon, FedEx, etc. are also looking forward to electrifying their medium and heavy-duty trucks soon. These vehicles, unlike passenger vehicles, are designed for long-distance routes and have an increased battery capacity according to their load carrying requirements. Owing to the range and battery capacity of these medium and heavy-duty vehicles DC fast charging is an absolute necessity for them.

Table 1. Comparison of Extremely Fast Charging (XFC) of EVs with Currently Available Charging Infrastructures. Reproduced from [55], U.S. Department of Energy: 2017.

\begin{tabular}{cccccc}
\hline Units & $\begin{array}{c}\text { Level 1 } \\
\mathbf{1 1 0 V} \mathbf{1 . 4} \mathbf{~ k W}\end{array}$ & $\begin{array}{c}\text { Level 2 } \\
\mathbf{2 2 0 V} \mathbf{7 . 2} \mathbf{~ k W}\end{array}$ & $\begin{array}{c}\text { DC Fast Charger } \\
\mathbf{4 8 0 \mathbf { V }} \mathbf{5 0} \mathbf{~ k W}\end{array}$ & $\begin{array}{c}\text { Tesla Supercharger } \\
\mathbf{4 8 0} \mathbf{~ V , ~ 1 4 0 ~ k W ~}\end{array}$ & $\begin{array}{c}\text { XFC } \\
\mathbf{8 0 0 + V}, \mathbf{4 0 0} \mathbf{~ k W}\end{array}$ \\
\hline $\begin{array}{c}\text { Range per minute of } \\
\text { charge (miles) }\end{array}$ & 0.082 & 0.42 & 2.92 & 8.17 & 23.3 \\
\hline $\begin{array}{c}\text { Time to charge for } \\
200 \text { miles (minutes) }\end{array}$ & 2143 & 417 & 60 & 21 & 7.5 \\
\hline
\end{tabular}


Currently, the US vehicle energy charging demand is estimated to be approximately 4.68 TWh [56]. According to a report published by Grid Integration Tech Team and Integrated Systems Analysis Tech Team in the US [57], if the high-end EV sales are to be considered by the year 2030, the energy generation capacity for US alone will be approximately 26 TWh. Furthermore, the Global EV Outlook 2020 by International Energy Agency [58] estimates the global EV charging requirement to be increasing from $79 \mathrm{TWh}$ to 550 TWh by 2030 considering the existing charging policies. If an aggressive sustainable development scenario is to be considered, the charging energy requirement can even increase up to approximately 1000 TWh by the year 2030. In the first quarter of 2021, $99.7 \%$ of the new power capacity in the United States was provided by PV and wind turbines [59]. This amounts to $4.5 \mathrm{GW}$ (2.9 GW for solar and 1.6 GW for wind energy) of installed energy generation capacity. If the same growth rate is to be considered, the PV and wind capacity can be multiplied by a factor of 4 for the whole year. This translates to $18 \mathrm{GW}$ of generation capacity (11.6 GW for solar and 6.4 GW for wind energy). Globally, solar and wind energy account for $270 \mathrm{GW}$ (127 GW for solar and $111 \mathrm{GW}$ for wind energy) of newer power generation capacity added by the end of the year 2020 according to the report by IRENA [60].

Considering an average $5 \mathrm{~h}$ of daily sunlight, in the US solar energy capacity can be estimated to be approximately $58 \mathrm{GWh}$ in the year 2021. The 5-h multiplicative factor is considered at the lower end considering variability of solar energy. This also correlates to an approximate $25 \%$ capacity factor for solar output. If the solar PV output is considered operating for $24 \mathrm{~h}$, the power output must be $(11.6 \times 24) 278.4 \mathrm{GWh}$. However, with a $25 \%$ capacity factor for solar PV it relates to approximately $70 \mathrm{GWh}$ of generated PV energy. In the case of wind energy also, if the capacity factor of $35 \%$ is to be considered to account for the variability, the total energy generation capacity amounts to approximately $(6.4 \times 24 \times$ $0.35) 54$ GWh of energy in the US. The increased utilization of PV power by coupling PV with battery-based storage systems can be seen in reference [61]. Thus, a combination of PV and battery systems for storage can enable PV systems to be utilized at a much higher efficiency than the 5-h multiplicative factor. An approximate $124 \mathrm{GWh}$ energy capacity for solar and wind energy is far from the energy requirement of 4.6 TWh energy requirement of EV charging demand in 2021. Globally, the solar PV and wind energy generation capacity with aforementioned capacity factor considerations can be estimated to be $762 \mathrm{GWh}$ and $932 \mathrm{GWh}$, respectively. The combined global PV and wind generation capacity of $1.7 \mathrm{TWh}$ is also far from the required 79 TWh energy for EV charging. Thus, there is an immense need to realize the gap between the generation capacity for these renewable sources to meet the EV charging demands of the 2030 projected requirements. In addition to the increased installed capacity requirement, it is essential to utilize the maximum efficiency of these systems in the most reliable solution. This section focusses on the need of a dedicated power network for the increased EV charging demands that emphasizes on the important metrics of efficiency and reliability. In this regard, the viability of a DC Fast Charging power network in terms of reliability, standardization, siting, adoption, availability of resources, and maximum efficiency is discussed in this section.

\subsection{System Reliability and Standardization}

Future charging stations of EVs will be the equivalent of what gas stations are to gasoline vehicles. Therefore, it is necessary to create a reliable fast charging power network while incurring minimum power losses. The existing electricity grid is based on an AC power network. DC Fast charging requires high voltage DC (around $480 \mathrm{~V}$ ) for DC charging. Therefore, the AC power from the grid is first converted to DC power in the charger and then utilized for charging. This can be seen in the block diagram in Figure 3. The AC components marked in Figure 3 are required for AC to DC conversion. In an earlier publication [19], we have already shown that typically $30 \%$ power is lost in AC to DC conversions. PV systems generate DC power and store DC power in batteries. Thus, if we utilize a PV and battery-based power network for DC fast charging, the need for 
conversion can be eliminated altogether. The unavailability of PV power during the night can cause this power network design to rely on battery-based storage systems heavily. The wind energy systems utilize DC conditioning to mitigate the variability in the generated alternating wind power. The DC-conditioned power is converted back to AC power and fed into the grid. Our system focusses on bypassing the AC grid to establish a novel and separate power network dedicated to DC fast charging. Thus, the DC conditioning stage for wind energy systems can be utilized for our proposed power network design. Apart from the power savings, there will be component cost saving involving AC to DC conversion components as shown in Figure 3. From a system's cost, energy efficiency and reliability point of view the components shown in red blocks of Figure 3 have adverse impact on all types of DC fast chargers. The elimination of the AC components from a charger can lead to reduced system area, decreased system costs, and increased efficiency and reliability. An example of increased reliability of employing DC power networks can be seen in reference [62]. The Onboard DC distribution system displays key benefits in terms of weight, electrical efficiency, component requirement, and reduced maintenance.

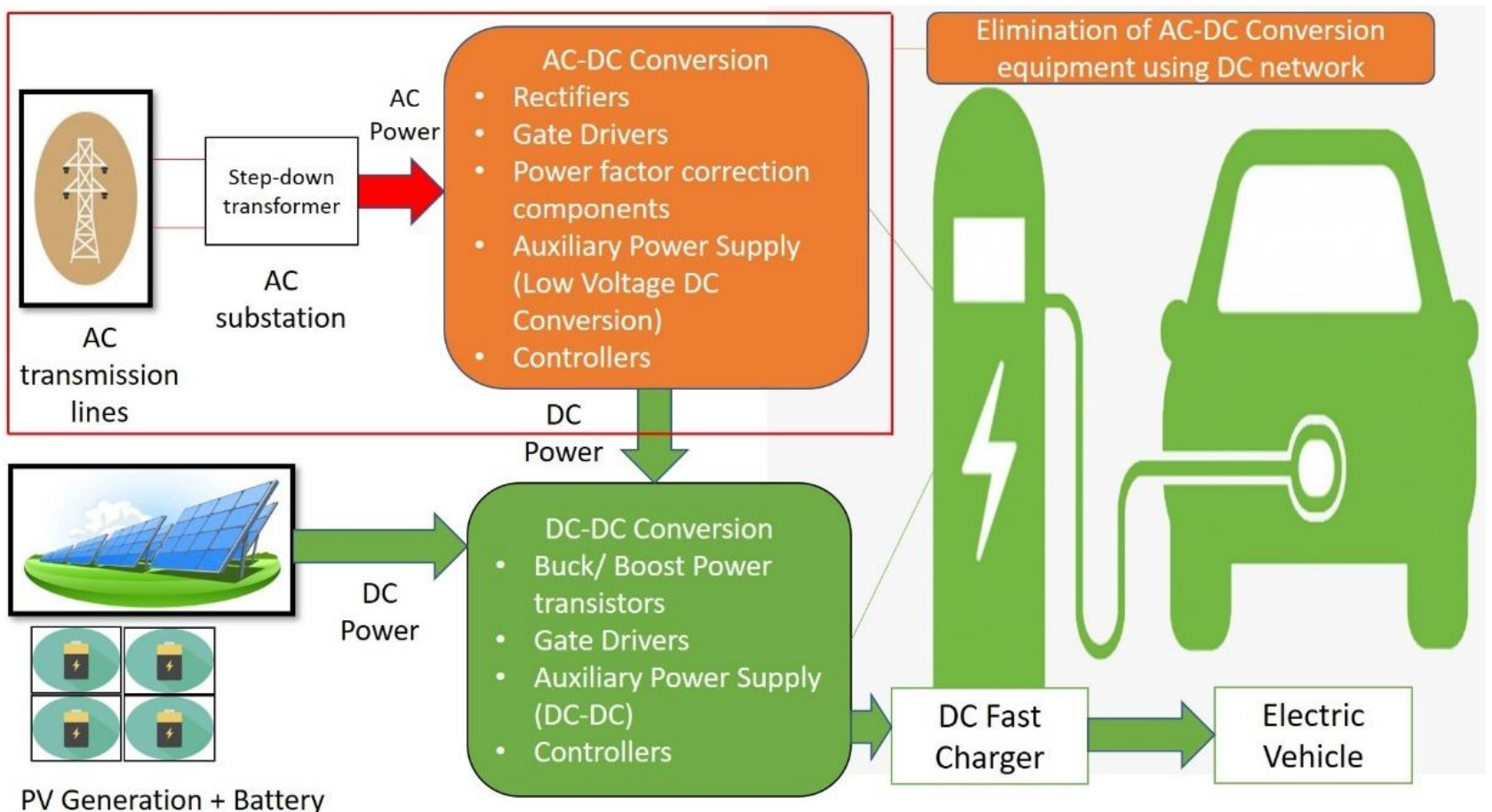

Storage

Figure 3. Functional block diagram of a DC Fast Charger.

Another issue with AC grid connected charging systems is synchronization. AC systems have frequency and phase components that need to be synchronized with that of the electricity grid. These synchronization characteristics vary from region to region and therefore, it is difficult to standardize the chargers across the globe. According to reference [63], standardization of charging infrastructure is one of the most dominant issues with EV charging. DC power networks do not have any such synchronization issue and can completely operate as a universal network without the need for conversion. Implementation of a uniform DC network can ultimately lead to standardization and incentivize the residential owners to motivate purchase of EVs. 


\subsection{Factors Impacting the Fast Charging Network}

The EV fast charging infrastructure is still in its nascent stage. The focus should be on deploying these chargers with maximum energy efficiency. The major decision criteria for EV charger deployment for highways are siting, enabling factor, and available power infrastructure [64]. The siting factor considers availability of EV chargers in public places. The enabling factor considers incentivizing EV charger in remote areas (highways). Finally, the availability of power infrastructure considers the availability of resources required for DC fast charging capability. Since our proposed charging network is dedicated to EV charging only, incentivizing charging is not a problem. Highways in the US and most of the world have plenty of nearby land. These land areas can be used to install a PV farm combined with battery banks for storage. Depending on the geographical terrain, the viability of complimentary wind energy systems can be considered. Availability of PV and wind power as energy resources is already discussed in the previous section.

The concern for our proposed power network is in commercial and residential places where there might not be enough area to deploy a PV/wind farm. The size of the PV/wind farm must be oversized to ensure stability during nighttime, wind variability, and for cloudy days. Sometimes, it is not practical to deploy a PV/wind farm of this size in a residential or commercial area. However, today high voltage DC transmission systems are cost-effective if a complete DC architecture is to be employed. Currently it is considered that for shorter distances AC lines are more cost-effective, after a certain distance (breakeven distance), HVDC lines are more economical. For overhead transmission, this distance is calculated to be approximately $600 \mathrm{~km}$ and $50 \mathrm{~km}$ for underground cables [65]. However, the cause of this distance-based economic analysis needs to be analyzed. An example for cost-estimation can be taken from the "Trans Australian HVDC Interconnector" [66]. The project employs a long-distance transmission line using HVDC to reduce congestion in the existing grid and neighboring states. Out of the total cost 1450 million Australian dollars (AUD 1.10 USD), the converter station accounts for 450 million Australian dollars (AUD 343 USD). The transmission lines itself amount to a cost estimation of AUD 617 million for a direct route of 870 miles. Thus, the transmission cost accounts for only AUD 0.7 million/mile. These financials are calculated based on cost factors from 2016. Today, these costs can be further reduced owing to large scale incorporation of HVDC projects across the globe. An important observation here is that the cost for converter stations for HVDC is more than HVAC terminal stations due to the conversion requirement from AC to DC and back from DC to AC to support the existing conventional grid system. In our case, if the conventional $\mathrm{AC}$ grid is to be taken out of the equation, then the terminal station costs for HVDC transmission can be further reduced. The elimination of AC conversion costs can enable the deployment of an economically viable DC infrastructure for charging stations in commercially crowded places where there is insufficient area for the installation of a PV/wind farm. This addresses the siting factor mentioned in reference [65]. Thus, all three decision criteria can be addressed using the proposed power network. A concept for this proposed network is shown in Figure 4, in which, EV charging stations are placed near solar/wind farms. It is possible to expand existing gas stations in some locations with solar/wind farms and fast DC chargers, where eventually gas stations will become obsolete. These stations can be accommodated even in commercially crowded places through HVDC transmission as shown in Figure 4. 


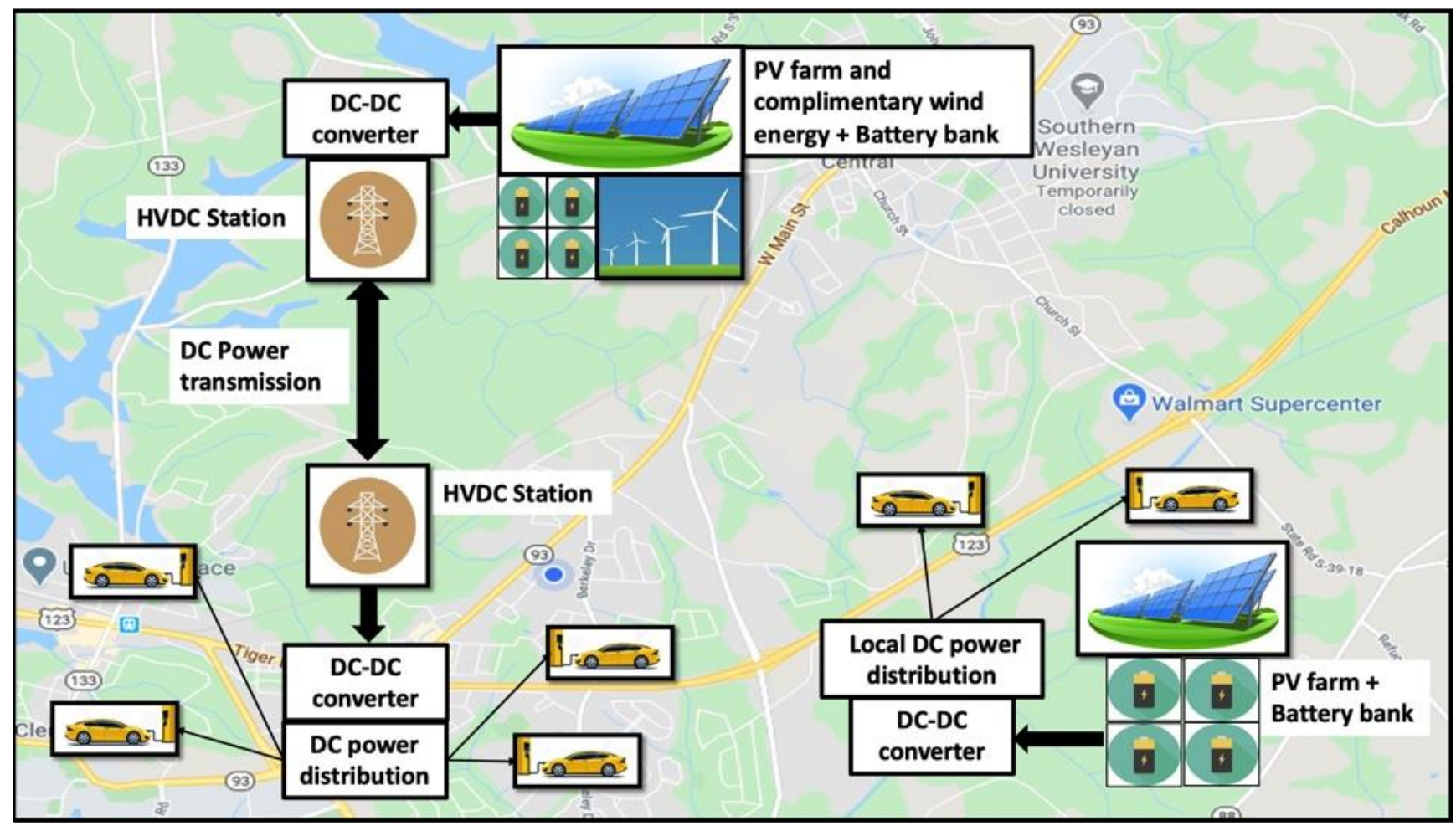

Figure 4. Concept of complete DC EV charging infrastructure.

\subsection{Efficiency of Fast Charging Power Network through Loss Minimization}

The proposed power network is also modelled to minimize conversion losses by employing DC-to-DC voltage conversions. As shown in Figure 5, the conventional AC grid-tied network deploys a total loss of $19 \%$ in the process of delivering PV generated power to the charging station. If the grid tied HVDC systems employed by the industry is to be deployed, the loss is comparable to the AC grid. Even though HVDC systems are deployed with the goal of reducing losses, this loss amounts to $19 \%$ due to multiple AC-to-DC and DC-to-AC conversion stages as illustrated in Figure 6. Our proposed HVDC model, however, deploys the same power at a 15\% loss for transmission via the existing AC infrastructure and at a $11 \%$ loss for a novel complete DC infrastructure. Moreover, a local network consisting of PV within the charger radius can implement the system at only a 3\% DC-DC converter loss. The loss considerations can be found in Appendix A.

In order to further reinforce our standpoint about conversion losses, an example of the recent Tesla V3 supercharger station was considered [67]. The station consists of 56 charging stalls at $250 \mathrm{~kW}$ rated power capacity. Assuming the entire power requirement is met through PV generation, the increase in conversion loss with increase in number of charging stalls is illustrated in Figure 6. At a smaller number of stalls, the power loss for generated PV power seems insignificant but at 56 stations the power loss is quite significant. 


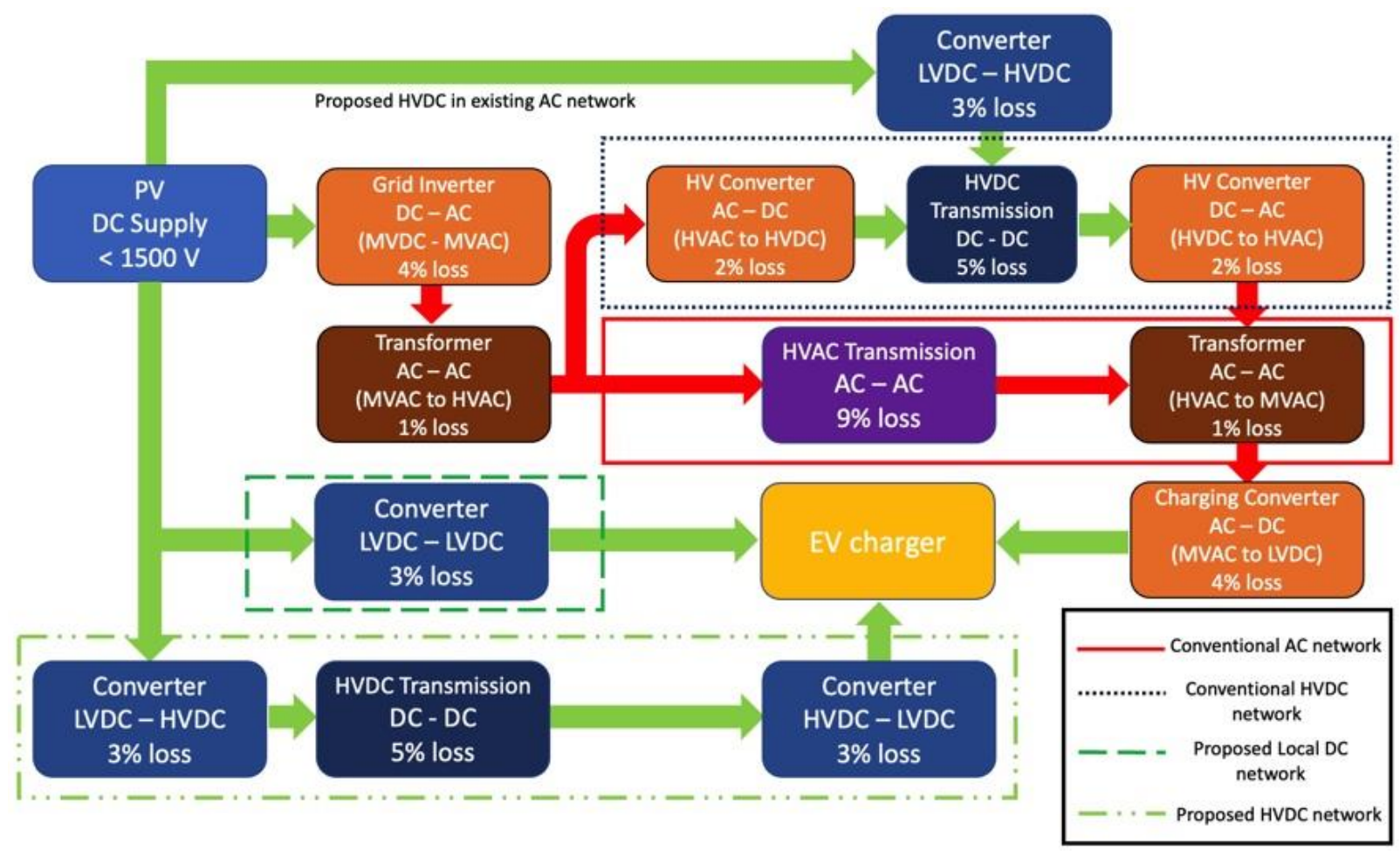

Figure 5. Power loss comparison for grid-tied DC fast chargers, in-practice HVDC systems, and proposed DC network.

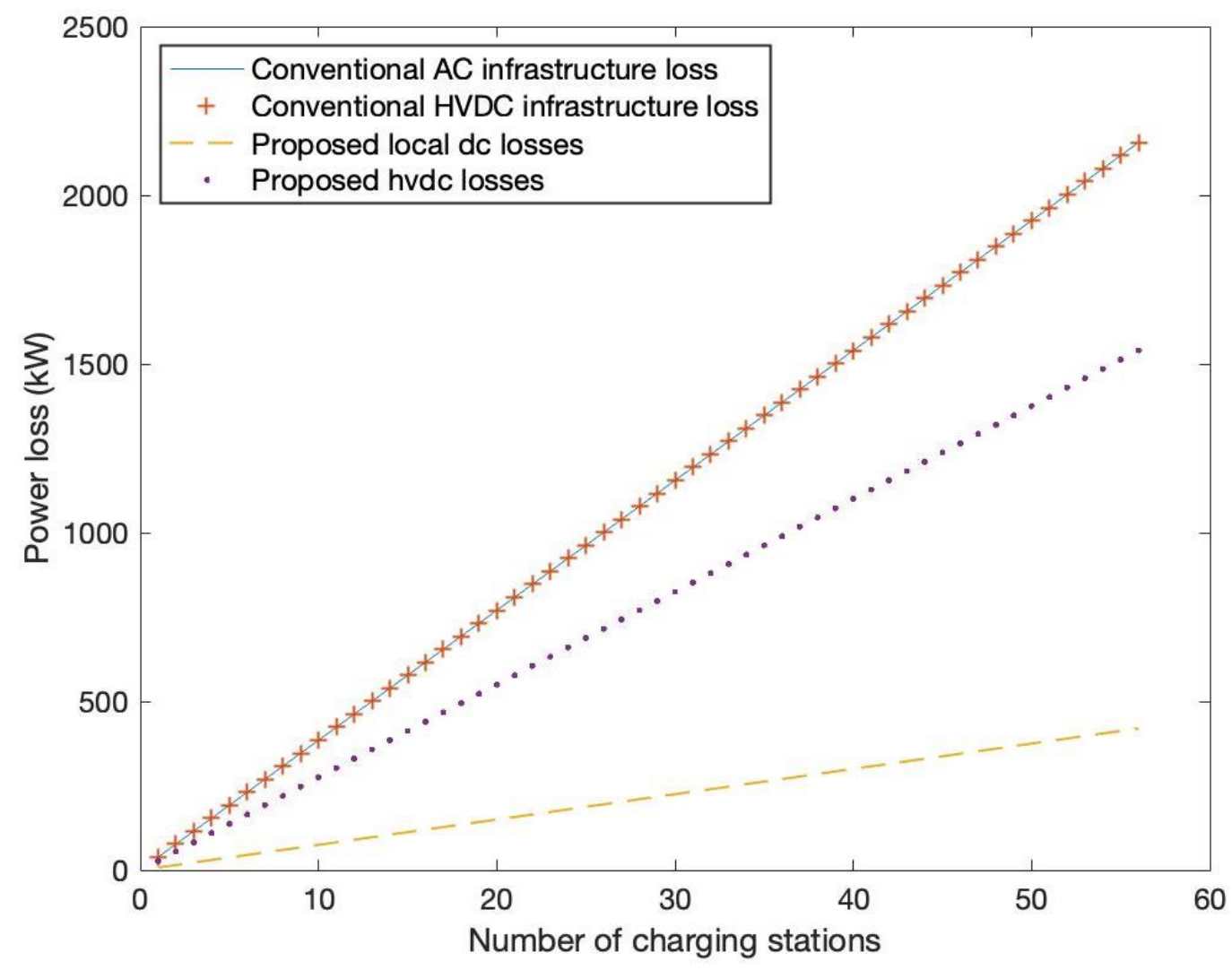

Figure 6. Increase in power loss with number of charging stalls. 


\section{Additional Factors to Reinforce the Proposed Charging Network}

Growth trends of electrification of transportation indicate that the sales of electric vehicles are growing than faster than expected [68]. This poses a major challenge for the power grid since the architectures of transmission and distribution grids are still focused on traditional design and operational rules [69]. Utilities need to invest in upgrading the power grid without triggering excessive upward pressure on consumer electric rates. In a recent study it was shown that the representative utility will need to make cumulative transmission and distribution investments of USD 2.8 billion through 2030, which translate to an estimated grid capacity upgrade cost of USD 2600 per EV [70]. Thus, without substantial increase in the cost of electrical power, utilities cannot provide low-rate electric power for charging of EVs. It is imperative to push for a novel design and architecture to sustain the load demand from EV charging. Thus, as proposed in the previous section, the DC power network can be an effective solution for this new demand. In this section, we discuss further advantages and innovations that will assist the proposed model.

\subsection{Role of Power Electronics}

As EV adoption increases exponentially, the supporting infrastructure must also grow to keep up with the increased utilization. The role of power electronics has always been crucial to any change in the power industry. Wide Bandgap (WBG) power transistors such as Silicon Carbide $(\mathrm{SiC})$ and Gallium Nitride $(\mathrm{GaN})$ transistors have been around for quite some time. However, the major cost advantage of Silicon-based transistors has always kept them at bay with respect to consumer applications. WBG transistors have superior operating characteristics as compared to Si MOSFETs. Depending on the operating requirements, their competition with Si MOSFETs is subjected to different WBG transistors. In this section, we will be discussing the viability of WBG transistors in the EV charging scenario.

Thermal conductivity is an important operating parameter when it comes to high voltage/high power applications. In a previous publication [71], we had illustrated a diagram for the ideal operating voltage ranges for different transistors. As seen in Figure 7, there is immense competition for the $400-800 \mathrm{~V}$ operating range. Si Power MOSFETs, $\mathrm{GaN}$ transistors, $\mathrm{SiC}$ transistors, and $\mathrm{Si}$ IGBTs are eligible to be utilized in that operating voltage range. This is the ideal voltage range that will be required to operate the DC-DC fast charging from the charger to the EV. Thus, the DC-DC conversion from the charger to EV requires power transistors that will provide the best operating characteristics. The GaN transistors provide a superior breakdown voltage and power dissipation for high frequency switching operation employed in DC-DC conversion. The SiC transistors have the best thermal conductivity but lack in high frequency operation. Despite these superior characteristics due to the larger bandgap in WBG power transistors, a new technology for $\mathrm{Si}$ transistors will be competing with these devices. These transistors, called Si Super-Junction transistors, have excellent power dissipation in the same operating voltage range. The most important factor in any technological battle is the operating cost in which the $\mathrm{Si}$ SJ transistors have a clear edge over the WBG devices. Thus, unless significant demand and manufacturing overhauls lead to a sharp decrease in the cost of WBG devices, the Si MOSFETs will continue to reign in this voltage range of operation. 


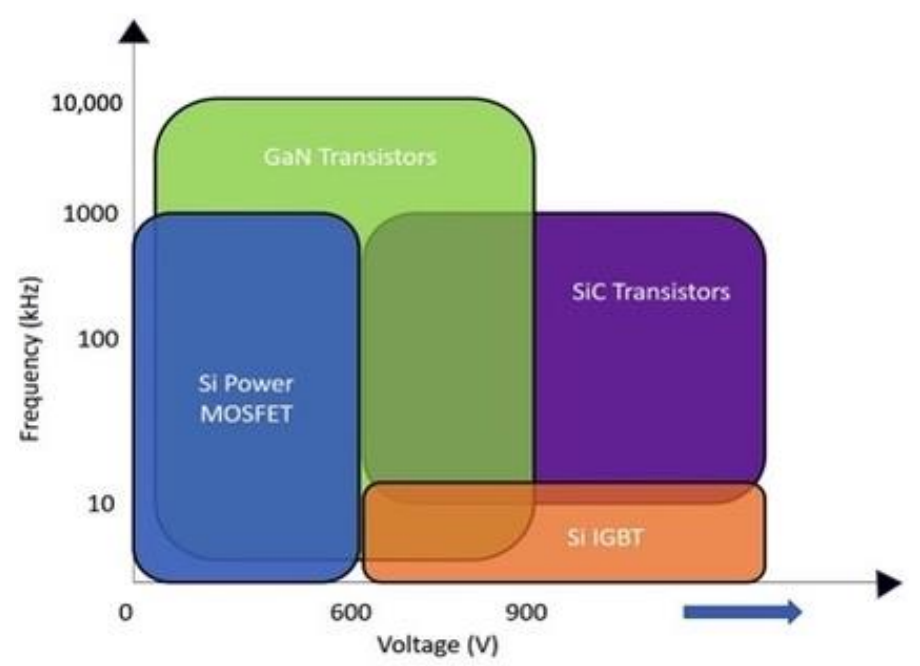

Figure 7. Approximate transistor operating voltage range vs. frequency of operation.

Although the existing market for EV charging seems to be dominated by Si MOSFETs owing to their cost advantage, in our proposed model there is a wider scope of application for WBG devices. In an entirely DC network, a DC-DC conversion stage will be required in the order of hundreds/few $\mathrm{kVs}$ to the order of hundreds of $\mathrm{kVs}$. This conversion will be in the HVDC-to-distribution and vice versa. The choice to be made will be between SiC transistors which show excellent power dissipation at high voltage operation and Si IGBTs that can match such characteristics. However, Si IGBTs are not capable of high frequency operation that will be required in the HVDC-DC conversion. Thus, this will open a new gateway for $\mathrm{SiC}$-based power electronics.

\subsection{Intelligent Charging Technologies and Related Opportunities}

The charging-discharging EV profiles and their impact on the grid are the next issues to be tackled by the new electrified transportation sector. The proposed smart charging mechanism involves several charging techniques to cope with the increased demand. These techniques are illustrated in Figure 8 [72]. As seen in Figure 8 [72], smart charging capabilities can range from basic on/off controlled charging to highly sophisticate automated control with dynamic pricing. The basic and V1G technologies are straightforward and need not be considered in this discussion. The V2G, V2H, and V2B are mechanisms that are going to impact the grid and the EV battery. There are several public policies incentivizing EV ownership and V2G opportunities, but at present there is no business case. The major highlight for V2G adoption policy is frequency regulation [73]. Storage systems enable efficient frequency regulation by increasing/decreasing generation or increasing/decreasing load demands [73]. Battery reserves through EV discharge are another benefit favoring V2G adoption to adhere to congestion in the grid during peak-demand hours. Lastly, V2G enables renewable energy integration by power quality conditioning, especially for wind energy [74]. Wind energy is more variable than sun, and EV battery systems can provide the necessary power quality conditioning for this variable power generation. Thus, the objective of policies favoring V2G applications is to successfully integrate EVs into the existing electricity grid. The real concern is whether the incentives for V2G outweigh the challenges associated with it. 


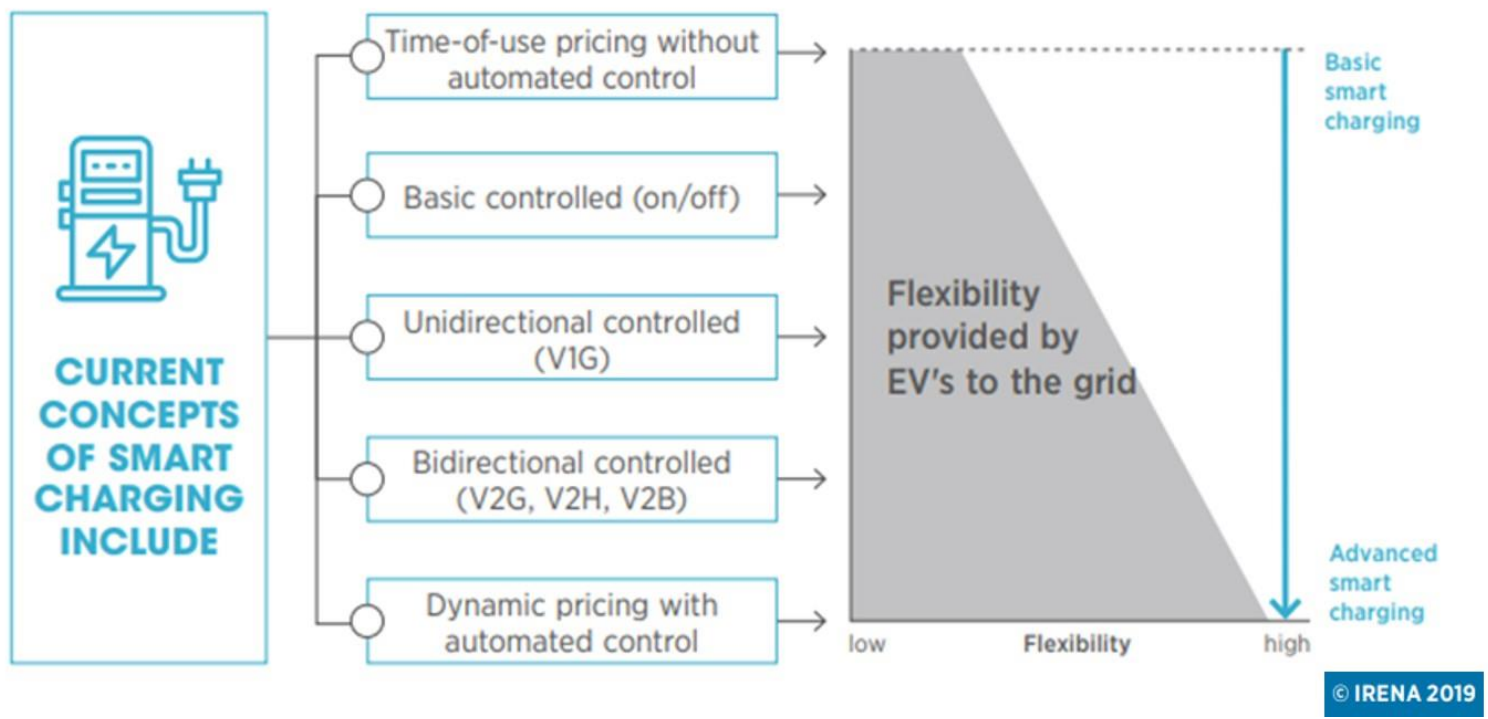

Figure 8. Smart charging as an enabler for EVs to provide flexibility to the grid. Reproduced from [72], IRENA: 2019.

The challenges associated with V2G are in the form of battery degradation, distribution equipment overload, and investment and energy losses [75]. Of these, the major challenge with V2G is the degradation of the EV battery. Continuous charging and discharging of the battery will have its adverse effect on the battery. Intricate control mechanisms will be required to maintain the battery State-of-Charge (SoC) at required levels to avoid degradation. Furthermore, increased charging cycles will ultimately affect the battery lifetime. Apart from the technical challenges to the battery, several network security and privacy issues are also summarized in reference [75]. It is understandable that exposing the vehicle battery to a central grid can open more possibilities of cyber-attacks. Monetary transactions associated with V2G incentives are another concern to adhere to with respect to their intricacies. Therefore, the viability of V2G application is questionable. In the proposed PV/wind and battery-based network for the charging infrastructure all these challenges can be eliminated. The need for V2G can be replaced by a V1G architecture to incentivize charging during minimum load and peak PV generating hours of the day. Further technical and policy work is required to make a V2G, V2H, and V2B business case.

\subsection{Intelligent Energy Management Systems}

The domain of artificial and computational intelligence has paved way for predictive control and intelligent energy management system (I-EMS) for EV charging. A sophisticated EMS is a hardware and software solution that implements multi-objective optimal control. The design of EMS can be categorized as either rule-based or modelbased/optimization-based techniques as explained in reference [76]. Rule-based algorithms are a set of constraints, either deterministic or fuzzy, that depend on the desired mode of operation. On the other hand, model-based or optimization-based algorithms define a single or multi-variate objective function or a model that is minimized or maximized as desired. Model-based optimization algorithms outperform traditional rule-based ones in terms of energy consumption reduction [77]. Computational intelligence paradigms, such as dynamic programming, neural networks, artificial immune systems, evolutionary computing, and swarm intelligence, are some model-based optimization algorithms that can be applied to design efficient real-time I-EMS for EV charging.

For the proposed charging infrastructure, the integration of I-EMS focuses on optimal dispatch of solar power and available co-located Lithium-ion battery storage to reduce conversion losses and provide charging on-demand. The main goal of the I-EMS is thus ensuring maximum utilization of the available solar irradiation for EV charging. Some secondary goals of the system can be increasing the co-located battery storage lifetime, ensuring optimal bi-directional power flow within a local community, minimizing trans- 
mission, and conversion losses etc. while performing desired EV charging. The I-EMS is responsible for providing a real-time estimate of the $\mathrm{SoC}$ and State-of-Health $(\mathrm{SoH})$ of the co-located battery storage. Since, $\mathrm{SoC}$ and $\mathrm{SoH}$ are not directly measurable, a reliable and accurate estimation strategy is needed in order to improve battery life. Furthermore, mitigating thermal degradation of batteries is another crucial function of the I-EMS. Furthermore, charge equalization among individual cells is vital to increase the overall battery performance. The I-EMS is also responsible for data acquisition, maintaining chargedischarge profiles, and safety protection of storage systems. The critical functions of I-EMS necessary for smooth EV operation are summarized in reference [78].

Integration of $\mathrm{PV}$, wind-based, or grid-tied charging schemes has led to additional parameters that need to be included in the EMS optimization strategy. Grid tied EV charging creates additional optimization parameters that are totally unnecessary for independent DC charging infrastructure. Active $(\mathrm{P})$ and Reactive $(\mathrm{Q})$ power balancing, energy scheduling for charging/discharging during peak load, reducing Rate of Change of Frequency (ROCOF) effects, single/three phase conversions, grid pricing, and demand-response incentives with off-peak and on- peak charging hours, line loading, over-voltage, and under voltage protection, are few of the many problems associated with grid-tied charging stations. These additional control parameters can be eliminated in a complete PV/windDC-based charging infrastructure with I-EMS. The power flow management between PV-DC generation and local charging can easily be optimized while ensuring SoC and $\mathrm{SoH}$ of the batteries with I-EMS. The intermittency of PV/wind charging is improved by oversizing and EMS controlled local battery storage at charging stations. This significantly reduces the computations and improves execution time for intelligent control.

A block-level representation of the proposed PV/wind-DC EMS is shown in Figure 9. The proposed EMS is a computational, information, and action engine that receives operational data from IoT sensors and prediction models, processes, and computes available information, and generates actionable commands for optimal power flow dispatch.

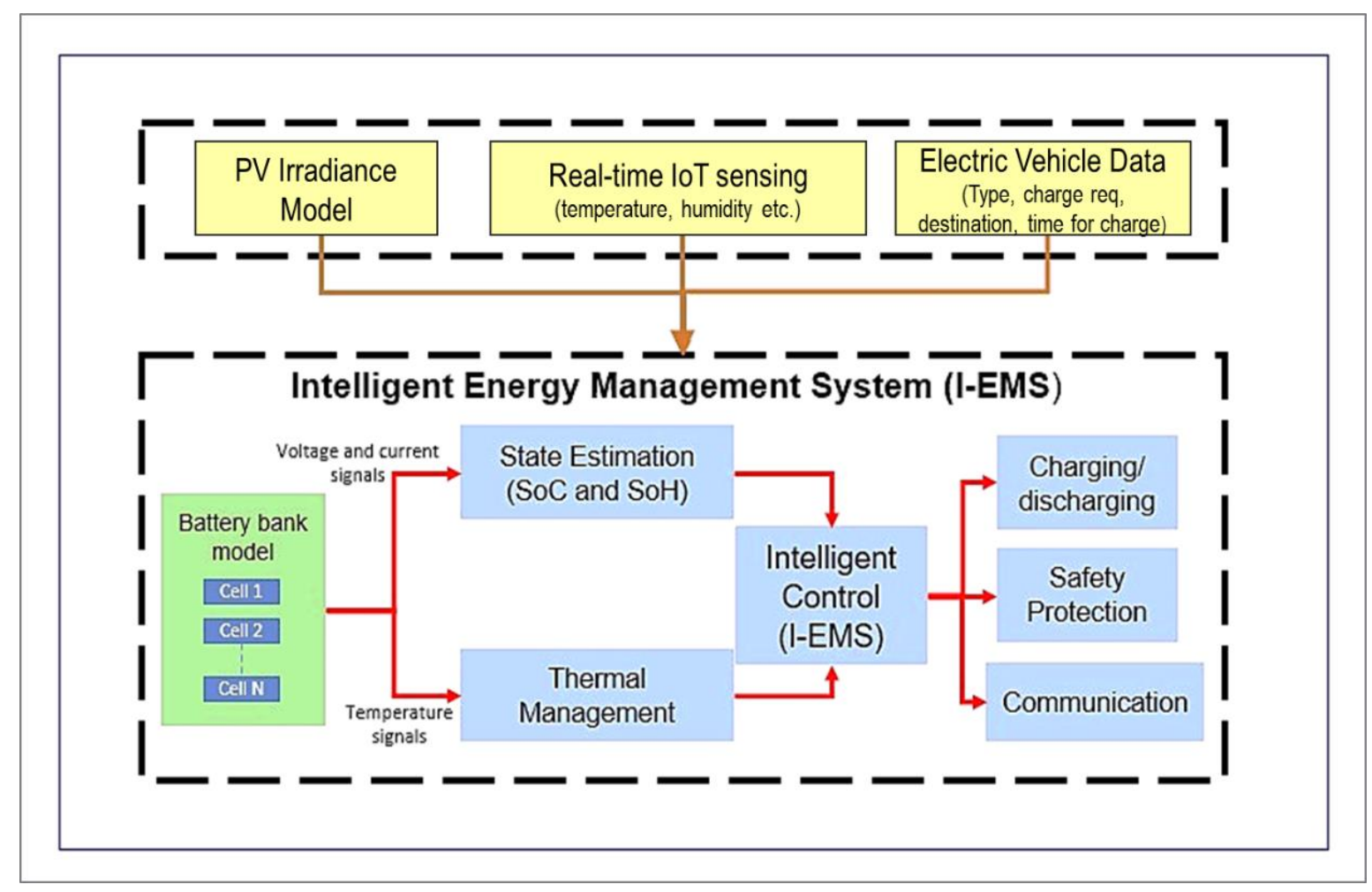

Figure 9. Block-level representation of PV-DC Intelligent EMS. 


\subsection{Communication and Internet of Things (IoT)}

The advent of IoT sensing and communication has transformed traditional power networks by providing an intelligent and cyber-enabled energy management system that provides access to affordable, clean, and sustainable energy for all. The charging infrastructure of EVs will be equipped with IoT sensors to monitor parameters, such as voltage, current, temperature etc. This will impart real-time feedback capabilities to the EV users for prompt charging decisions regarding battery life cycle and degradation profile. IoT sensing and control with improved communication techniques will enhance resiliency of PV-DC charging infrastructure for EVs. Various IoT-based sensor techniques are available for monitoring solar energy grids for maximum power efficiency. An elaborate review of integrating IoT with electric power and energy systems is given in reference [79].

Improved IoT sensing is critical for accurate calculation of the battery SoC. Different methods proposed to calculate the battery $\mathrm{SoC}$, such as Coulomb counting (CC), impedance measurement, fuzzy logic, artificial neural network, and model-based estimation methods (such as Kalman Filtering (KF), Extended KF, Particle Filtering Etc.), require IoT monitoring. Predictive and preventive maintenance of batteries is also made possible with IoT techniques. Thus, IoT is a crucial component of Energy Management System for EVs. Advances in communication and IoT strategies will continue to improve the DC charging infrastructure for the EVs.

\section{Conclusions}

The proposed PV and or wind turbines and battery-based power network is the most cost-effective solution for creating a sustainable infrastructure for the electrification of transportation. A complete DC-based system is the most efficient implementation strategy taking into consideration the technical and economic requirements of the charging infrastructure. If the local generation of DC power is not practical, then the long-haul power transmission mechanism must also be DC-based. With a complete end-to-end DC network, we can eliminate the power losses incurred in the existing infrastructure and reduce the ultimate charging cost of EVs. Grid synchronization concerns can be eliminated and the impact on the grid, due to the large scale of EV incorporation, can also be avoided. The increased energy efficiency of the proposed DC power network compared to the current $\mathrm{AC}$ infrastructure implies that there will be immense reductions in the components and materials required for power generation, transmission, and distribution. This further reinforces the utilization of the proposed network to enable sustainability of the power network. The future adoption of WBG electronics and intelligent energy management systems in our proposed network will be the key to various technical and economic benefits. Thus, it is important to realize that rather than implementing strategies and policies to incorporate a DC-based charging system to an existing AC grid, it is more feasible to implement a novel sustainable DC power network. A PV, wind, and batterybased network can not only meet the changing demands with greatest efficiency, but also ensure clean generation of power towards a clean and sustainable future. It is important to realize the importance of innovative implementation strategies at the nascent stages rather than incorporating the global electrification of transportation sector in the current aging infrastructure. Existing infrastructures might contain the new demand for the near future but will ultimately succumb to the increasing strain of the new energy demand. Moreover, under-developed and developing countries, which aspire to achieve climate goals through electrification of transportation, must realize the advantages outlined in this paper. The existing infrastructure is already strained in such nations and cannot handle increased power demands of such magnitude. Instead, it will be immensely beneficial to establish low-cost novel infrastructures rather than trying to bolster the existing unreliable infrastructure. 
Author Contributions: Conceptualization, P.P. and R.S.; methodology, P.P.; software, P.P.; validation, P.P., V.P. and R.S.; formal analysis, R.S.; investigation, P.P.; resources, P.P. and V.P.; data curation, P.P.; writing — original draft preparation, P.P. and V.P.; writing—review and editing, P.P. and R.S.; visualization, P.P. and R.S.; supervision, R.S.; project administration, R.S. All authors have read and agreed to the published version of the manuscript.

Funding: This research received no external funding.

Institutional Review Board Statement: Not applicable.

Informed Consent Statement: Not applicable.

Data Availability Statement: Not applicable.

Conflicts of Interest: The authors declare no conflict of interest.

\section{Appendix A}

The loss percentages for the calculations are as follows:

1. LVDC-LVDC converter losses: The efficiency ratings for low voltage DC-DC converters are cited up to $98 \%$ in recent times [80]. Furthermore, voltage ranges from 9 to $420 \mathrm{~V}$ are achieved at $93 \%$ efficiency [80]. In our case, we are considering dedicated state of the art DC-DC converters (possible WBG implementation). Hence, the efficiency is considered up to $97 \%$ as seen in reference [81].

2. PV inverter MVDC-MVAC loss: The efficiency rating of $96 \%$ is considered as per current industry standards [82].

3. Transformer MVAC-HVAC-MVAC converter loss: A 1\% loss value is considered for non-ideal practical scenario.

4. HVAC-HVDC-HVAC converter and HVDC transmission loss: The comparable losses for a $400 \mathrm{kV}$ overhead AC transmission line to a $500 \mathrm{kV} \mathrm{HVDC}$ transmission line are $9.4 \%$ to $6 \%$, respectively [83]. Hence, in our case, they are considered as $9 \%$ for AC transmission lines and 5\% for HVDC transmission lines considering the HVDC lines can go up to $800 \mathrm{kV}$ for $2.3 \%$ losses [83]. The HVDC converter station losses are outlined for Voltage Source Converter (VSC up to 350kV) and Current Source Converter (CSC up to $800 \mathrm{kV}$ ) as $1 \%$ and $0.7-0.8 \%$ per converter end, respectively [84]. Thus, to gain the independent power control advantage associated with VSCs, stateof-the-art WBG-enabled version of this technology is utilized. The loss per converter end is assumed to be $2 \%$ for up to $500 \mathrm{kV}$.

5. LVDC-HVDC -HVDC converter losses: In this conversion topology, a 1\% intermediate DC-to-DC conversion stage loss and $2 \%$ intermediate stage-to-HVDC conversion loss is considered as per reference [85]. These losses can be further reduced considering state-of-art (possible WBG) incorporation. However, for the purpose of industrial practicality, a 3\% value is finalized.

6. Charger-based MVAC_LVDC inverter losses: A $250 \mathrm{~kW}$ Tesla supercharger is claimed to deploy an efficiency of $96 \%$, thus rendering a loss of $4 \%$ [86].

\section{References}

1. EPA: Sources of Greenhouse Gas Emissions. Available online: https:/ /www.epa.gov/ghgemissions/sources-greenhouse-gasemissions (accessed on 28 June 2021).

2. IEA: Clean Energy Innovation. Available online: https://www.iea.org/reports/clean-energy-innovation (accessed on 28 June 2021).

3. CleanTechnica: This Stunning Chart Shows Why Battery Electric Vehicles Win. Available online: https://cleantechnica.com/2020 /06/10/this-stunning-chart-shows-why-battery-electric-vehicles-win/ (accessed on 25 August 2021).

4. NEMA CURRENTS: Challenges and Opportunities in Electrified Transportation. Available online: https://blog.nema.org/2020 /05/07/ challenges-and-opportunities-in-electrified-transportation/ (accessed on 28 June 2021).

5. Electrek: Tesla Announces Model 3 Performance Range Increase in China. Available online: https://electrek.co/2020/06/29 / tesla-model-3-performance-range-increase-china/ (accessed on 28 June 2021). 
6. Kornsiriluk, V. Study of Energy Storage System: Concept of using ESS in EV charging stations in MEA. In Proceedings of the 2019 IEEE PES GTD Grand International Conference and Exposition Asia (GTD Asia), Bangkok, Thailand, 19-23 March 2019; pp. 697-700.

7. Vaisambhayana, S.; Tripathi, A. Study of electric vehicles penetration in Singapore and its potential impact on distribution grid. In Proceedings of the 2016 Asian Conference on Energy, Power and Transportation Electrification (ACEPT), Singapore, 25-27 October 2016; pp. 1-5.

8. Mauri, G.; Bertini, D.; Fasciolo, E.; Fratti, S. The impact of EV's fast charging stations on the MV distribution grids of the Milan metropolitan area. In Proceedings of the 22nd International Conference and Exhibition on Electricity Distribution (CIRED 2013), Stockholm, Sweden, 10-13 June 2013; p. 1266.

9. Quirós-Tortós, J.; Ochoa, L.F.; Lees, B. A statistical analysis of EV charging behavior in the UK. In Proceedings of the 2015 IEEE PES Innovative Smart Grid Technologies Latin America (ISGT LATAM), Montevideo, Uruguay, 5-7 October 2015 ; pp. $445-449$.

10. Urbanelli, A.; Sallati, A.; Ciasca, F.; Aluisio, B.; Vergine, C.; Zeni, L.; Petrucci, M.; Forte, G.; Trovato, M. Electric vehicle grid impacts Opportunities and evaluation on the Italian Transmission Grid. In Proceedings of the 2018 AEIT International Annual Conference, Bari, Italy, 3-5 October 2018; pp. 1-6.

11. Sasidharan, C.; Tyagi, B.; Das, S. Evaluating Time of Use rates for Electric Vehicle Charging for Distribution Companies in India. In Proceedings of the 2019 IEEE Transportation Electrification Conference (ITEC-India), Bengaluru, India, 17-19 December 2019; pp. 1-5.

12. Guo, Y.; Bashash, S. Analyzing the impacts of Plug-in EVs on the California power grid using quadratic programming and fixed-point iteration. In Proceedings of the 2017 American Control Conference (ACC), Seattle, WA, USA, 24-26 May 2017; pp. 2060-2065.

13. Jiang, Z.; Tian, H.; Beshir, M.J.; Sibagatullin, R.; Mazloomzadeh, A. Statistical analysis of Electric Vehicles charging station usage and impact on the grid. In Proceedings of the 2016 IEEE Power \& Energy Society Innovative Smart Grid Technologies Conference (ISGT), Minneapolis, MN, USA, 6-9 September 2016; pp. 1-5.

14. Tu, R.; Gai, Y.J.; Farooq, B.; Posen, D.; Hatzopoulou, M. Electric vehicle charging optimization to minimize marginal greenhouse gas emissions from power generation. Appl. Energy 2020, 277, 115517. [CrossRef]

15. Muñoz, E.; Jabbari, F. A decentralized, non-iterative smart protocol for workplace charging of battery electric vehicles. Appl. Energy 2020, 272, 115187. [CrossRef]

16. Sachan, S.; Deb, S.; Singh, S. Different charging infrastructures along with smart charging strategies for electric vehicles. Sustain Cities Soc. 2020, 60, 102238. [CrossRef]

17. Khalid, M.; Alam, M.; Sarwar, A.; Asghar, M.S. A Comprehensive review on electric vehicles charging infrastructures and their impacts on power-quality of the utility grid. ETransportation 2019, 1, 100006. [CrossRef]

18. Ardeshiri, A.; Rashidi, T. Willingness to pay for fast charging station for electric vehicles with limited market penetration making. Energy Policy 2020, 147, 111822. [CrossRef]

19. Paniyil, P.; Singh, R.; Asif, A.; Powar, V.; Bedi, G.; Kimsey, J. Transformative and disruptive role of local direct current power networks in power and transportation sectors. Electron. Energetics 2019, 32, 387-402. [CrossRef]

20. Buresh, K.M.; Apperley, M.D.; Booysen, M.J. Three shades of green: Perspectives on at-work charging of electric vehicles using photovoltaic carports. Energy Sustain. Dev. 2020, 57, 132-140. [CrossRef]

21. Microgrid Knowledge: Energy Waste Worries American Businesses Now. Available online: http://energyefficiencymarkets.com/ energy-waste-worries-american-businesses / (accessed on 28 June 2021).

22. Union of Concerned Scientists: Report Finds That 'Advanced' Nuclear Reactor Designs Are No Better than Current ReactorsAnd Some Are Worse. Available online: https://www.ucsusa.org/about/news/report-advanced-nuclear-reactors-no-bettercurrent-fleet (accessed on 28 June 2021).

23. CleanTechnica: Fukushima's Final Costs Will Approach a Trillion Dollars just for Nuclear Disaster. Available online: https:/ / cleantechnica.com/2019/04/16/fukushimas-final-costs-will-approach-one-trillion-dollars-just-for-nuclear-disaster/ (accessed on 28 June 2021).

24. The Wallstreet Journal: West Risks Blackouts as Drought Reduces Hydroelectric Power. Available online: https: / /www.wsj.com/ articles / west-risks-blackouts-as-hydroelectric-power-dries-up-11624008601 (accessed on 25 August 2021).

25. ThoughtCo: Thomas Edison: Champion of Renewable Energy. Available online: https://www.thoughtco.com/thomas-edisonchampion-of-renewable-energy-1204180 (accessed on 28 June 2021).

26. Our World in Data: Why Did Renewables Become So Cheap So Fast? And What Can We Do to Use This Global Opportunity for Green Growth? Available online: https:/ / ourworldindata.org/cheap-renewables-growth (accessed on 25 August 2021).

27. Paniyil, P.; Singh, R.; Powar, V.; Deb, N.; Zhang, J.; Bai, K.; Dubey, A. Batteries and Free Fuel based Photovoltaics and Complimentary Wind Energy based DC Power Networks as 100\% Source of Electric Power around the Globe. In Proceedings of the 48th IEEE Photovoltaic Specialists Conference, Virtual Conference, Honolulu, HI, USA, 20-25 June 2021.

28. PV Magazine: Saudi Arabia's Second PV Tender Draws World Record Low Bid of \$0.0104/kWh. Available online: https: //www.pv-magazine.com/2021/04/08/saudi-arabias-second-pv-tender-draws-world-record-low-bid-of-0104-kwh/ (accessed on 25 August 2021). 
29. Fu, R.; Remo, T.; Margolis, R. Evaluating the cost benefits of US utility-scale photovoltaics plus energy storage systems. In Proceedings of the 2018 IEEE 7th World Conference on Photovoltaic Energy Conversion (WCPEC) (A Joint Conference of 45th IEEE PVSC, 28th PVSEC \& 34th EU PVSEC), Waikoloa, HI, USA, 10-15 June 2018; pp. 1-4.

30. BloombergNEF: Battery Pack Prices Fall as Market Ramps Up with Market Average at \$156/kwh in 2019. Available online: https: / / about.bnef.com/blog/battery-pack-prices-fall-as-market-ramps-up-with-market-average-at-156-kwh-in-2019/ (accessed on 28 June 2021).

31. Asif, A.; Singh, R. Further Cost Reduction of Battery Manufacturing. Batteries 2017, 3, 17. [CrossRef]

32. Aljazeera: Tesla is Working on Making Electric Cars Less Expensive. Available online: https://www.aljazeera.com/amp/ ajimpact/tesla-working-making-electric-cars-expensive-200514181336609.html (accessed on 28 June 2021).

33. Popular Mechanics: Tesla's Battery Cell Patent Is 'Way More Important than It Sounds'. Available online: https://www. popularmechanics.com/science/a32433420/elon-musk-tesla-battery-cell-patent/ (accessed on 28 June 2021).

34. Energy Storage: Battery Storage at US \$20/MWh? Breaking Down Low-Cost Solar-Plus-Storage PPAs in the USA. Available online: https: / / www.energy-storage.news/blogs/battery-storage-at-us20-mwh-breaking-down-low-cost-solar-plus-storageppas (accessed on 28 June 2021).

35. CleanTechnica: LA \& 8Minute Solar Ink Lowest Cost Solar-Plus-Storage Deal in US History. Available online: https:// cleantechnica.com/2019/09/11/la-8minute-solar-ink-lowest-cost-solar-plus-storage-deal-in-us-history/ (accessed on 28 June 2021).

36. NREL: 2018 U.S. Utility-Scale Photovoltaics Plus-Energy Storage System Costs Benchmark. Available online: https://www.nrel. gov/docs/fy19osti/71714.pdf (accessed on 25 August 2021).

37. Powar, V.; Singh, R. Stand-Alone Direct Current Power Network Based on Photovoltaics and Lithium-Ion Batteries for Reverse Osmosis Desalination Plant. Energies 2021, 14, 2772. [CrossRef]

38. Fastmarkets: Power Rates Drive US Aluminum Industry's Future. Available online: https://www.amm.com/Article/3541758/ Power-rates-drive-US-aluminum-industrys-future.html (accessed on 28 June 2021).

39. Jin, Y.; Behrens, P.; Tukker, A.; Scherer, L. Water Use of Electricity Technologies: A Global Meta-Analysis. Renew. Sustain. Energy Rev. 2019, 115, 109391. [CrossRef]

40. USC News: The U.S. Energy System Uses a Lot of Water-But Exactly How Much? Available online: https://news.usc.edu/1485 41/energy-consumption-requires-a-lot-of-water-but-just-how-much/ (accessed on 25 August 2021).

41. IEA: Global Water Consumption in the Energy Sector by Fuel Type in the Sustainable Development Scenario, 2016-2030. Available online: https: / www.iea.org/data-and-statistics / charts/global-water-consumption-in-the-energy-sector-by-fuel-type-in-thesustainable-development-scenario-2016-2030 (accessed on 25 August 2021).

42. NRDC: Fossil Fuels: The Dirty Facts. Available online: https://www.nrdc.org/stories/fossil-fuels-dirty-facts (accessed on 28 June 2021).

43. CleanTechnica: 1.7 Million Children Die Every Year from Unhealthy Environments, WHO Reports. Available online: https: / / cleantechnica.com/2017/03/07/1-7-million-children-die-every-year-unhealthy-environments-reports/ (accessed on 28 June 2021).

44. CleanTechnica: Childhood Leukemia and Oil \& Gas Development Strongly Associated; Research Finds. Available online: https: //cleantechnica.com/2017/02/20/childhood-leukemia-oil-gas-development-strongly-associated-research-finds / (accessed on 28 June 2021).

45. Powar, V.; Singh, R.; Paniyil, P. Nearly Free Sustainable Electric and Thermal Power for Desalination. In Proceedings of the 2020 Clemson University Power Systems Conference (PSC), Clemson, SC, USA, 10-13 March 2020; pp. 1-8.

46. Asif, A.A.; Singh, R.; Venayagamoorthy, G.K. Ultra-Low Cost, and Solar Storms Secured Electricity Infrastructure to Address Climate Change Challenges for all Economies. In Proceedings of the 2016 Clemson University Power Systems Conference (PSC), Clemson, SC, USA, 8-11 March 2016; pp. 1-7.

47. Solar Power World: How the Solar Industry is Responding to the Increasing Intensity of Natural Disasters. Available online: https: / / www.solarpowerworldonline.com/2018/01/solar-industry-responding-increasing-intensity-natural-disasters / (accessed on 28 June 2021).

48. Scientific American: High -Altitude Nuclear Explosions Dangerous, but not for Reasons Gingrich Cites. Available online: https:// blogs.scientificamerican.com/observations/high-altitude-nuclear-explosions-dangerous-but-not-for-reasons-gingrich-cites / (accessed on 28 June 2021).

49. IEA: SDG7: Data and Projections. Available online: https://www.iea.org/reports/sdg7-data-and-projections/access-toelectricity (accessed on 28 June 2021).

50. MapsofIndia.com. World Population Density Map. Available online: https://www.mapsofindia.com/worldmap/populationdensity (accessed on 28 June 2021).

51. Global Solar Atlas. Available online: https://globalsolaratlas.info (accessed on 28 June 2021).

52. Behabtu, H.; Messagie, M.; Coosemans, T.; Berecibar, M.; Fante, K.; Kebede, A.; Mierlo, J. A Review of Energy Storage Technologies' Application Potentials in Renewable Energy Sources Grid Integration. Sustainability 2020, 12, 10511. [CrossRef] 
53. PNNL: 2020 Grid Energy Storage Technology Cost and Performance Assessment. Available online: https://www.pnnl.gov/sites/ default/files/media/file/Final\%20-\%20ESGC\%20Cost\%20Performance\%20Report\%2012-11-2020.pdf (accessed on 25 August 2021).

54. IEEE Smart Grid: Green Hydrogen: Challenges for Commercialization. Available online: https://smartgrid.ieee.org/newsletters / february-2021/green-hydrogen-challenges-for-commercialization (accessed on 25 August 2021).

55. U.S. Department of Energy, Office of Energy Efficiency \& Renewable Energy: Enabling Fast Charging: A Technology Gap Assessment. Available online: https:/ / www.energy.gov/sites/prod/files/2017/10/f38/XFC\%20Technology \%20Gap \%20Assessment\% 20Report_FINAL_10202017.pdf (accessed on 28 June 2021).

56. Statista: U.S. Electric Vehicle Energy Charging Demand between 2020 and 2035. Available online: https://www.statista.com/ statistics/952069/electric-vehicle-charging-energy-demand/ (accessed on 25 August 2021).

57. US Drive: Grid Integration Tech Team and Integrated Systems Analysis Tech Team: Summary Report on EVs at Scale and the U.S. Electric Power System. Available online: https:/ / www.energy.gov/sites/prod/files/2019/12/f69/GITT\%20ISATT\%20EVs\%20 at\%20Scale\%20Grid\%20Summary\%20Report\%20FINAL\%20Nov2019.pdf (accessed on 25 August 2021).

58. IEA: Global EV Outlook 2020. Available online: iea.org/reports/global-ev-outlook-2020 (accessed on 25 August 2021).

59. CleanTechnica: New Power Capacity in the USA-January-March 2021. Available online: https://cleantechnica.com/2021/06/ 14/solar-wind-power-99-7-of-new-us-electricity-capacity-in-1st-quarter-of-2021/ (accessed on 25 August 2021).

60. IRENA: Renewable Capacity Statistics 2021. Available online: https://www.irena.org/publications/2021/March/RenewableCapacity-Statistics-2021 (accessed on 25 August 2021).

61. Paniyil, P.; Powar, V.; Singh, R.; Hennigan, B.; Lule, P.; Allison, M.; Kimsey, J.; Carambia, A.; Patel, D.; Carrillo, D.; et al. Photovoltaics-and Battery-Based Power Network as Sustainable Source of Electric Power. Energies 2020, 13, 5048. [CrossRef]

62. ABB: The Step Forward: Onboard DC Grid. Available online: https://new.abb.com/docs/librariesprovider91/articles/lm00614 -onboard-dc-grid-brochure_june2014_1.pdf (accessed on 25 August 2021).

63. Das, H.; Rahman, M.M.; Li, S.; Tan, C. Electric vehicles standards, charging infrastructure, and impact on grid integration: A technological review. Renew. Sustain. Energy Rev. 2020, 120, 109618. [CrossRef]

64. Palomino, A.; Parvania, M. Advanced charging infrastructure for enabling electrified transportation. Electr. J. 2019, 32, 21-26. [CrossRef]

65. Kalair, A.; Abas, N.; Khan, N. Comparative study of HVAC and HVDC transmission systems. Renew. Sustain. Energy Rev. 2016, 59, 1653-1675. [CrossRef]

66. Bartlett, S. Trans-Australian HVDC interconnection investigation. In Proceedings of the 2016 IEEE PES Asia-Pacific Power and Energy Engineering Conference (APPEEC), Xi'an, China, 25-28 October 2016; pp. 666-670.

67. Electrek: Tesla Opens World's Largest Supercharger Station. Available online: https:/ / electrek.co/2020/11/14/tesla-opensworlds-largest-supercharger-station/ (accessed on 25 August 2021).

68. BCG: Who Will Drive Electric Cars to the Tipping Point? Available online: https://www.bcg.com/publications/2020/driveelectric-cars-to-the-tipping-point (accessed on 28 June 2021).

69. Anastasiadis, G.; Kondylis, G.; Polyzakis, A.; Vokas, G. Effects of increased electric vehicles into a distribution network. Energy Procedia 2019, 157, 586-593. [CrossRef]

70. BCG: The Costs of Revving Up the Grid for Electric Vehicles. Available online: https://www.bcg.com/publications/2019/costsrevving-up-the-grid-for-electric-vehicles (accessed on 28 June 2021).

71. Paniyil, P.; Singh, R. Emerging Role of Silicon Carbide and Gallium Nitride Based Power Electronics in Power and Transportation Sectors. ECS Trans. 2019, 92, 3. [CrossRef]

72. IRENA: Electric-Vehicle Smart Charging. Available online: https://irena.org/-/media/Files/IRENA/Agency/Publication/2019 /Sep/IRENA_EV_smart_charging_2019.pdf (accessed on 28 June 2021).

73. Yannick, P.; Marc, P.; Willett, K. A public policy strategy for electric vehicles and for vehicle to grid power. In Proceedings of the 2013 World Electric Vehicle Symposium and Exhibition (EVS27), Barcelona, Spain, 17-20 November 2013; pp. 1-10.

74. Yilmaz, M.; Krein, P.T. Review of benefits and challenges of vehicle-to-grid technology. In Proceedings of the 2012 IEEE Energy Conversion Congress and Exposition (ECCE), Raleigh, NC, USA, 15-20 September 2012; pp. 3082-3089.

75. Saxena, N.; Grijalva, S.; Chukwuka, V.; Vasilakos, A.V. Network security and privacy challenges in smart vehicle-to-grid. IEEE Wirel. Commun. 2017, 24, 88-98. [CrossRef]

76. Panday, A.; Bansal, H.O. A review of optimal energy management strategies for hybrid electric vehicle. Int. J. Veh. Technol. 2014, 2014, 160510. [CrossRef]

77. Wei, C.; Hofman, T.; Caarls, E.I.; van Iperen, R. Evolution and classification of energy and thermal management systems in electrified powertrains. In Proceedings of the 2019 IEEE Vehicle Power and Propulsion Conference (VPPC), Hanoi, Vietnam, 14-17 October 2019; pp. 1-6.

78. Aruna, P.; Vasan, P.V. Review on Energy Management System of Electric Vehicles. In Proceedings of the 2019 2nd International Conference on Power and Embedded Drive Control (ICPEDC), Chennai, India, 21-23 August 2019; pp. 371-374.

79. Bedi, G.; Venayagamoorthy, G.K.; Singh, R.; Brooks, R.R.; Wang, K.C. Review of Internet of Things (IoT) in electric power and energy systems. IEEE Internet Things J. 2018, 5, 847-870. [CrossRef] 
80. Vicor: High Energy, High Density, DC-to-DC Converters. Available online: http:/ /www.vicorpower.com/high-density-highefficiency-dc-dc-converters (accessed on 25 August 2021).

81. Agamy, M.; Harfman-Todorovic, M.; Elasser, A.; Steigerwald, R.; Sabate, J.; Chi, S.; McCann, A.; Zhang, L.; Mueller, F. A High Efficiency DC-DC Converter Topology Suitable for Distributed Large Commercial and Utility Scale PV Systems. Available online: https:/ / www.osti.gov/servlets/purl/1059296 (accessed on 25 August 2021).

82. Aurora: Inverter Efficiency Curves. Available online: https://help.aurorasolar.com/hc/en-us/articles/115001389928-InverterEfficiency-Curves (accessed on 25 August 2021).

83. Siemens: High Voltage Direct Current Transmission Factsheet. Available online: https://assets.new.siemens.com/siemens/ assets/api/uuid:d5c5f4ae-d9f6-49e9-b68b-85bb7ceb4f41/factsheet-hvdc-e.pdf (accessed on 25 August 2021).

84. National Grid: High Voltage Direct Current Electricity Factsheet. Available online: https://www.nationalgrid.com/sites/default/ files/documents / 13784-High\%20Voltage \%20Direct $\% 20$ Current $\% 20$ Electricity $\% 20 \%$ E2\%80\%93\%20technical $\% 20 \mathrm{information}$. pdf (accessed on 25 August 2021).

85. Schoen, A.; Bakran, M.-M. Comparison of the most efficient DC-DC converters for power conversion in HVDC grids. In Proceedings of the PCIM Europe 2015, International Exhibition and Conference for Power Electronics, Intelligent Motion, Renewable Energy and Energy Management, Nuremberg, Germany, 19-21 May 2015; pp. 1-9.

86. Cleantechnica: Tesla Upgrading Its Supercharging Network to V3 For Next-Generation Speeds. Available online: https: / / cleantechnica.com/2019/03/04/tesla-upgrading-its-supercharging-network-to-v3-for-next-generation-speeds / (accessed on 25 August 2021). 